\title{
XXXVII. Additional remarks on the state in which alcohol exists in fermented liquors
}

\section{William Thomas Brande Esq.}

To cite this article: William Thomas Brande Esq. (1813) XXXVII. Additional remarks on the state in which alcohol exists in fermented liquors , Philosophical Magazine Series 1, 42:185, 211-215, DOI: $10.1080 / 14786441308638318$

To link to this article: http://dx.doi.org/10.1080/14786441308638318

册 Published online: 27 Jul 2009.

Submit your article to this journal $₫$

Џll Article views: 2

Q View related articles ๘ 
that two old species, the paliurus and the ceanothus, which germinate only during the secoud and ihird years in the sowings annually made at the Museum, ruse at the end of a few days. Dots not this prove that many perennials, like the pairurus, ceanothus, \&c. do not come up until the second or third year, because the embryo bas not yet attained its necessary degree of maturity? or that the juices contained in the colyledons are not sufficiently elaborated,rather than admit, as has been done generally, that the envelopes of the seeds are tor hard, and cannot be pierced by the embryo until two or three years expire? This opinion appears to me so much the more erroneous, as, in most fruits or seeds the valves or envelope open naturally, and without any effort : it can only be admitted in a very small number of circumstances; and 1 shall add in favour of mine, a fact which was related to me by $M$. Thouin the elder, the accuracy of which is well known, namely, that gardeners always prefer for melon beds, such seeds as have been two or three years gathered, to those of the preceding year.

XXXVII. Additional Remarks on the State in which Alcohol exists in fermented Liquors. By Wruliam Tromas Brande, Esq. F.R.S.*

$T$ HE experiments and observations contained in this paper are intended as supplementary to a communication on the same subject, which the Royal Society has done me the honour to insert in the Philosophical Transactions for the bear $1811+$.

On that occasion, I endeavoured to refute the commonly received opinion respecting the production of alcohol during the distillation of fermented liquors, by showing that the results of the process are not affected by a variation of temperature equal to twenty degrees of Fahrenheit's scale; that is, that a similar quantity of alcohol is afforded by distilling wine at $180^{\circ}$ and at $200^{3}$.

$I$ also conceived that any new arrangement of the ultimate elements of the wine, which could have given rise to the formation of alcohol, would have been attended with other symptonis of decomposition, that carbon would have been deposited, or carbonic acid evolved, which in the experiments alluded to was not the case. Upon such grounds I ventured to conclude, that the relative quantity of alcohol

* From the Philosophical Transactions for 1813, part $i$.

f. Philosophical I'ransactions, page 337. 
in wines might be estimated by submitting them to a careful distillation, and by ascertaming the specific gravity of the distilled liquor with the precautions which I have formerly described.

This conclusion may be objected to, by supposing that the lowest temperature, at which the distillations were performed, was sufficient for the formation of alcohol from the elements existing in the wine; but it is not easy to conceive how this should bappen, without sume of those other changes which I have just noticed.

It has been stated, in my former paper, that the separation of alcohol from wine, by the addition of subcarbonate of potash, is prevented by the combination of the alkaline salt with the colouring-extractive, and acid contained in the liquor. I have also shortly noticed some unsuccessful attempts to separate these substances by otber means than distillation.

In prosecuting the inquiry, this difficnlty has been surmounted, and I shall proceed to show that alcohol may be separated from wine without the intervention of heat, and that the proportion thus afforded is equal to that yielded by distillation.

When the acetate*, or subacetatet of lead, or the subnitrate of tint are added to wine, a densc insoluble precipitate is quickly formed, consisting of a combination of the metallic oxide with the acid and colouring-extractive matter of the wine; and when this is separated by filtration, a colourless fluid is obtained, containing alcohol, water, and a portion of the acid of the metallic salt, provided the latter has not been added in excess, in which case a part remains undecomposed.

The acetate of lead and the subnitrate of tin produce the desired effect of separating the colouring and acid matters, in the greater number of instances; but they are less rapid and perfect in their action, and not so generally applicable as the subacetate of lead $\S$, which is the substance that I commonly employed.

The following experiment was made with a view to ascertain the effect of this salt.

* Sugar of lead.

+ Formed by boiling two parts of sugar of lead with one of finely powdered litharge, in six parts of water. The solution should be preserved in well closed phials, as it is rapidly decomposed by attracting carbonic acid from the atmosphere. Even while hot, a portion of carbonate of lead is formed in it.

$\neq$ Prepared by dissolving protoxide of tin in cold dilute nitric acid.

$\$$ The effect of this salt upon colouring matter was first pointed out to me by Mr. E. M. Noble, of Chedsea. 
Twenty measures of alcohol, specific gravity ,82500, were mixed with eighty measures of distilled water coloured with logwood, and rendered slightly acid by supertartrate of potash. Four measures of a concentrated solution of the subacetate of lead were added to bis mixture, and the whole poured upon a filter. A precipitate $n$ as thus collected of a deep purple colour, which appeared to consist of oxide of lead combined witb tariaric acid and the colouring-extractive matter.

The filtered liquor was perfectly transparent and colourless, and afforded, on the addition of subcarbonate of potash, 19,5 measures of alcohol*.

Finding that the separation of alcohol by subcarbonate of potash from mixtures of spirit and "ater was nearly complete, and that colouring-extractive matter and tartaric acid might be removed from such mixtures by the subacetate of lead, I proceeded to examine wine by such modes of analysis.

The following results were obtained by these and other comparative experiments.

1. One pari by measure of a concentrated solution of subacetate of learl was added to eight measures of common port wine: the mixture having been agitated for a few minutes, was poured upon a filter.-The filtrated liquor was perfectly colourless, and the addition of dry subcarbonate of potash effected a rapid separation of alcohol $\uparrow$.

One hundred measures of the wine thus treated afforded 22,5 measures of alcohol.

2. Eight ounces of the wine employed in the last experi-

* Pure subcarbonate of potash, obatined by igniting the carbonate, was employed in these experiments. I found that about 19,3 parts of alcohol were separated in the course of four hours, by the addition of 50 parts of the subcarbotiate to a mixture of 20 parts of alcohol by measure with 80 of distilled water, and that no further separation took place. The alcohol is always slightly alkaline, probably from containing a snall portion of the solution of the subcarbunate, or of pure sodat; but as this did not interfer with the object of the experiment, it was not particularly artended to.

When the subcarbonate was added to a mixiure of four parts by mensure of alcohol with 96 of water, no separation was effected.-A mixture containiug 8 per cent. of alcohol aforded about 7 parts-one cuntaining 16 per cent, abuut 15,5, and where the proportion of atcohol exceedrd 16 per cent. the quantity, indicated by the action of the subcarbonate, was always within 0,5 per cent. of the real proportion contaiked in the nixture. So that in the examination of wines containing le-s than 12 per cent. of alcoboll, the method described in the text is somewhat exceptionable. The above experiments were made in glas, tube; varying in diameter from 0.5 inch to 2 inches, and accurately graduated inio ioc parts.

+. When any excess of the subacetate had been employed, a portion of carbonate of lead was thrown down; but this did not interfere with the subsequent separation of the alcohol. 
214 On the State in which Alcohol exists in fermented Liquors.

ment were distilled in glass vessels, as described in my former paper. - The specific gravity of the distilled liquor at the temperature of $60^{\circ}$ was 0,07530 , which indicates 22,30 per cent. by measure of alconol of the specific gravity of, 8250 .

3. Fight onnces of the same wine were introduced into a retort placed in a sand heat, and the process of distillation was stopped when six ounces had passed over into the receiver. After the vessels were completely cooled, the portion in the receiver was added to the residuum in the retort. The spccific gravity of this mixture (ascertained with proper piccautions) was, 9884 , that of the original wine $=0,9883^{*}$.

When care was taken to prevent the escape of vapnur, no change of specific gravity was produced in the wine $b_{j}$ three repetitions of the above process.

Similar experiments were repeated upon Madicira, sherry, claret, and vin de grave, wines differing in the relative proportions of alcohol, colourng mater, and acid which they contain, and the resulis wrere as decisive; so that $I$ conceive it is amply proved, by experimental evidence, that no alcohol is formed during the distillation of wines, and that the whole quantity found, alter distillation, pre-existed in the fermented liquor.

It has been frequently asserted, that a nixture of alcohot and water, in the proportions I have stated then to exist in wine, would be much more effectua! in producing intoxication, and the general bad effects of spirtuous liquors; than a similar quantity of the wine isself. But this is true to a very limited extent only: when brandy is aded to water, it is some time before the two liquids fierlectly combine, and with alcohol this is more renuarkably the case; and these mixtures are warmer to the taste, and more heating, if taken in this state of imperfect mion, than when stifficient time has been allowed for their yerfect mutual penetration.

I have also ascertained that distilled port wine tastes stronger, and is more heating than the wine in its original state, and that these qualities are impaired, and the wine reduced nearly to its original flavour, by the addition of its acid and extracive matter. With claret, and some other wines, containing less alcohol and more acid than port, these circumstances are more readily percived; and lastly, if the residuum afforded by the distillation of 100 parts of

- This experiment was suggested in the Edinburgh Review for Novembes 1811 . 
port wine be added to 22 parts of alcohol and 88 of water (in a state of perfect combination), the mixture is precisely analogous in its intoxicating effects to port wine of an equal strength.

In the table annexed to my former paper, it appears that the average quantity of alcohol contained in port wine amounts to $\geq 3,48$ per cent.; but two of the wines there alluded to are stronger than any I have since met with, and were at that time sent to me as "remarkably strong and old port." I have lately examined a number of specimeus of the better kinds of port wine in common use, and the results of these experiments lead me to place the average strength of 22 per cent. of alcohol by measure.

A port wine procured for me by Dr. Baillie, and to which no brandy had been added, afforded 21,40 per cent. of alcohol: another specimen of a similar description, put into my hands by an Oporto merchant, contained only 19 per cent.; it is the weakest port wine I have met with.

The other results given in the table agree perfectly with those of subsequent and more extended experiments.

XXXVIII. On Electricity by Position or Induction. By Ez. WALKER, Esq.

To Mr. Tilloch.

Dear Str,-IN my paper on Mr. Bennet's Electrometer, I asserted that electricity by position or induction* does not vanish as soon as the electric is removed, though Professor Robison and other writers on electricity are of a contrary opinion.

The Professor observes, that "the mechanical phænomena of electricity may be expressed in a few simple propositions. The most general fact that we know, and from which all the rest may be deduced, is the following.

"If anv body $A$ is electrified by anv means whatever, and if anuther body B" (supported by an insulating stand) " is brought into its neighbourhood, the last becomes electrified by position.

"The mere vicinity of the electric renders the conductor electric, and the elsctricity ceases on removing the excited surface.$+ "$

* "It will he convenient," says Dr. Robison, "to distinguish this last electrical state by a particular name. We wiil call it Eiertricty ly pusition. or Inducel Electrealy. It is indnced by position with regard to the permanently electrical body." - Encycl. Sup. vol. i. p. 568 .

† Encycl. Brit. Sup. rol, i. p. 571 . 